Journal of Business \& Management (COES\&RJ-JBM)

ISSN (E): 2306-7179 ISSN (P): 2306-8043

Publisher: Centre of Excellence for Scientific \& Research Journalism, COES\&RJ LLC

Online Publication Date \& Issue: 1st October 2016, Vol.4, No.4, October 2016

http://centreofexcellence.net/J/JBM/JBM\%20Mainpage.htm

\title{
The Impact of Internal Audit in the Protection of Accounting Information Systems in Commercial Banks in Jordan
}

\author{
Dr. Ayman Saleh Mustafa Harb \\ Department of Accounting - Faculty of Economics and Administrative Sciences \\ Assistant Professor ( Zarqa University - Jordan)
}

\begin{abstract}
:
This study aimed to identify the impact of internal audit in the protection of accounting information systems in commercial banks in Jordan, the researcher designed a questionnaire consisting of (28) items, which were distributed to the constituent of the commercial banks to study in Jordan community, and the number (5) commercial banks by the end of 2015, noting that the study where there is no option for a sample of the community, set it the study included all members of society, and represented the unit of analysis to individuals working in the accounting departments (financial, accountants, managers), circles and other sections in the commercial banking sector by the end of 2015, were distributed (100) to identify the individuals working in these departments and sections.
\end{abstract}

This study has concluded that there is a statistically significant effect (second hypothesis) to the effect of internal audit in the protection of accounting information systems in commercial banks in Jordan, where he reached the relationship between two variables value (0.654), and considers this value is statistically significant, because the value of ( $\mathrm{f}$ ) calculated the (67.85) have a statistically significant level of significance (0.000), which is less than (5\%), and indicate this result to the impact of internal audit in the protection of accounting information systems in commercial banks in Jorda.

As well as the study concluded that there is a statistically significant effect (for the second hypothesis) to the effect of internal audit in the accounting information security rules in commercial banks in Jordan, where he reached the relationship between two variables value (0.631), and considers this value is statistically significant, because the value of ( $f$ ) calculated the (60.09) have a statistically significant level of significance $(0.000)$, which is less than (5\%), and indicate this result to the impact of internal audit in the accounting information security rules in commercial banks in Jordan.

As well as the study concluded that there is a statistically significant effect (for the third hypothesis) to the effect of internal auditing in enhancing the appreciation and awareness of staff in commercial banks in Jordan, where he reached the relationship between two variables value (0.397), and considers this value is statistically significant, because the value of ( $f$ ) calculated the (17.05) have a statistically significant level of significance (0.000), which is less than (5\%), and indicate this result to the impact of internal auditing in enhancing the appreciation and awareness of staff in commercial banks in Jordan.

Keyword:

Internal Audit, Protection of Accounting Information Systems, Commercial Banks

Citation:

Harb , Dr. Ayman Saleh Mustafa (2016); The Impact of Internal Audit in the Protection of Accounting Information Systems in Commercial Banks in Jordan (COES\&RJ-JBM) Vol.4, No.4, pp.151-171

This work is licensed under a Creative Commons Attribution 4.0 International License. 


\title{
أثر التدقيق الداخلي في حماية أنظمة المعلومات المحاسبية في البنوك التجارية في الإردن

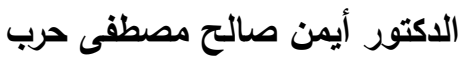

\author{
استاذ المساعد في كلية الإقتصاد والعلوم الإدارية - قسم المحاسبة - جامعة الزرقاء - الإردن \\ مشروع بحث استكمالاً لمنطلبات البحث العلمي في جامعة الزرقاء - لعام 2016

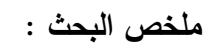

هدفت هذه الدراسة للتعرف على أثز التدقيق الداخلي في حماية أنظمة المعلومات المحاسبية في البنوك

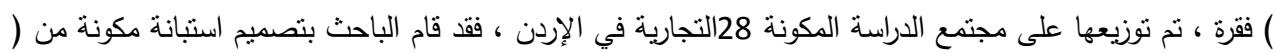

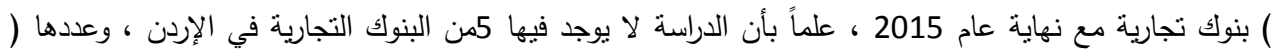

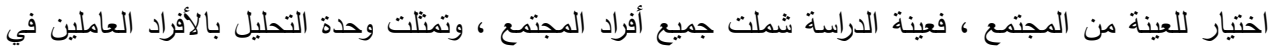

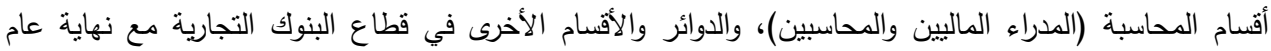

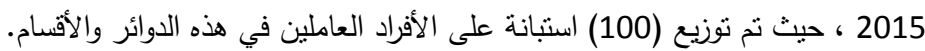

وقد توصلت هذه الدراسة إلى أنه يوجد تأثير ذات دلالة إحصائية (للفرضية الإولى) لتأثير التدقيق الداخلي التئي

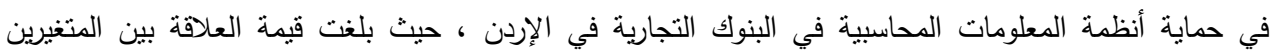

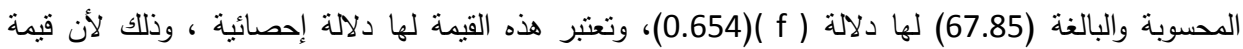
إحصائية بمستوى دلالة (0.000)، وهو أقل من (5\%) ، وتتشير هذه النتيجة إلى أثر التنقيق الداخلي في حماية أنظمة المعلومات المحاسبية في البنوك التجارية في الإردن.

وكذلك توصلت هذه الدراسة إلى أنه يوجد تأثير ذات دلالة إحصائية (للفرضية الثانية) لتأثير التدقيق فئن

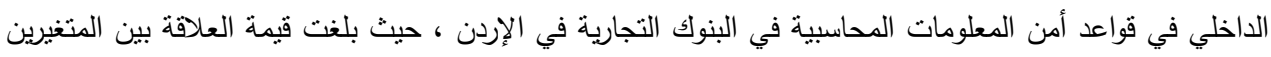

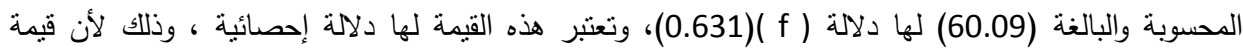

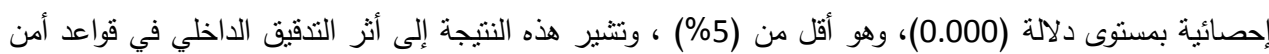
المعلومات المحاسبية في البنوك التجارية في الإردن.

وكذلك نوصلت هذه الدراسة إلى أنه يوجد تأثثر ذات دلالة إحصائية (للفرضية الثالثة) لتأثير التدقيق التئ

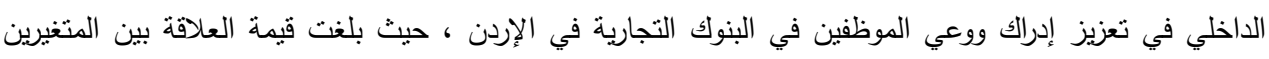

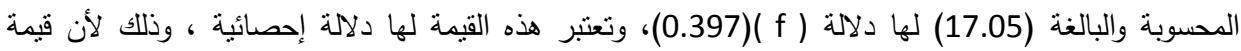

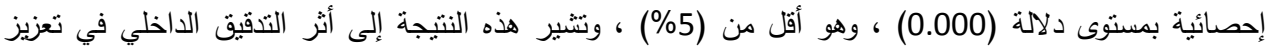
إدراك ووعي الموظفين في البنوك التجارية في الإردن.

الكلمات المفتاحية : التدقيق الداخلي- حماية أنظمة المعلومات المحاسبية - البنوك التجارية.

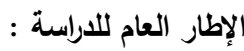

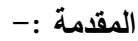

إن العبرة الأساسية في تخطيط التتمية الاقتصادية في جميع المتمعات ، وكذلك في انثاء المشروعات تثمنل في مدى سلامة هذه المشروعات ومدى حدواها وارتكازها على مبادىء عملية ودراسات مدعمة بالارقام والبيانات 
والجداول الدقيقة ، ولكي ينم الحفاظ على مدى صحة البيانات والكفاءة التتغيلية، تم الاهتمام بالتدقيق الداخلي وخاصة في السنوات الخمس الأخيرة للحفاظ على حقوق الأخرين.

فقد ازدادت في الآونة الأخيرة أهمية التدقيق الداخلي لدى شركات التأمين وتطورت أفاق استخداماته وخاصة

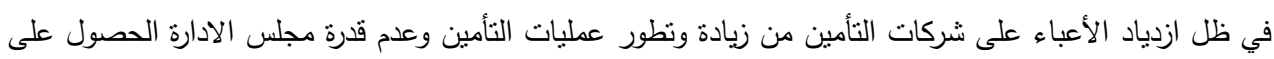

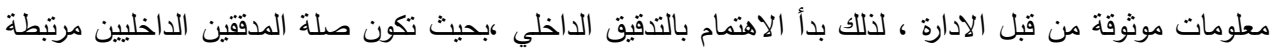

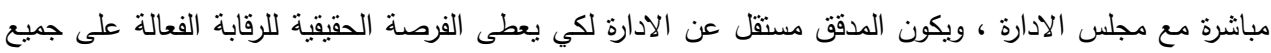
اليبانات المالية والتتغيلية الخاصة بالثركة.

وتعتبر المعلومات أصل ذو قيمة مشتركة ، والذي يجب أن تتم حمايته بعناية واهتمام لأن استمرارية العمل ونجاحه يعتمدان على سلامة والتوفر المستمر للمعلومات الخطيرة. ان الاعتماد على المعلومات والتكنولوجيا المتغيرة

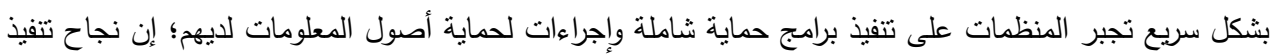

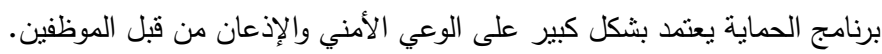

أصبحت المعلومات بحد ذاتها من السلع أو المصادر الأكثر أهمية للعديد من المنظمات. الفثل في

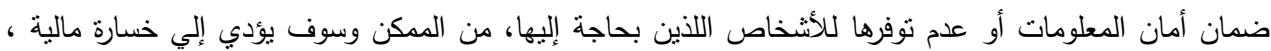

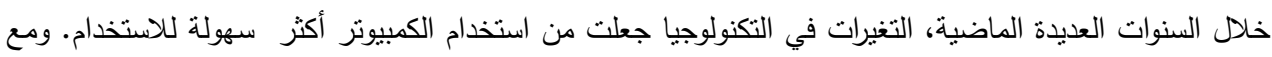
ذللك، قام مستخدمو النظام المسالمون بإنشاء مهام محددة منعلقة بتأمين الأمان والسلامة لأنظمة الاتصال والكمبيوتر ،

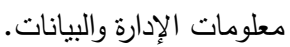

بالرغم من القيام بجهود مضنية من قبل محاسبين متمرسين لتقليل خطر الإصابة بمثل هذه الحوادث، هناك

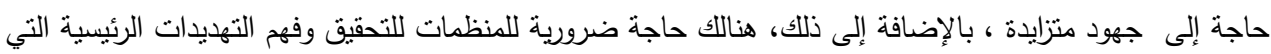

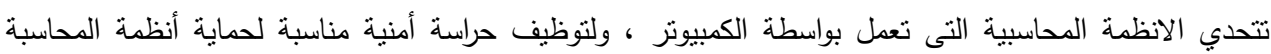

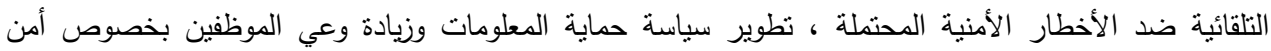
المعلومات ومواضيع مهمة جداً. يؤثر التذقي الداخلي في حماية أنظمة المعلومات المحاسبية على قطاع البنوك التجارية في الاردن، والذي

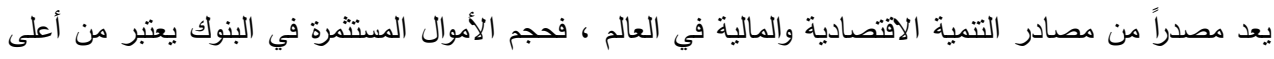

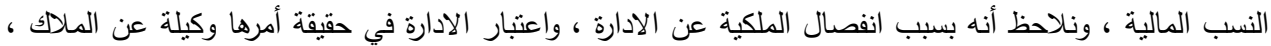

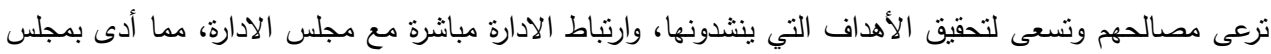

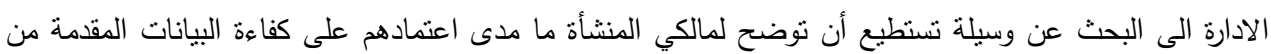

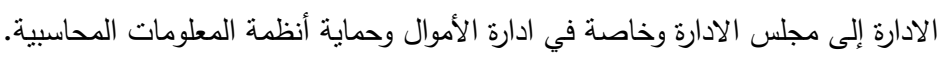




$$
\text { أهداف الدراسة :- }
$$

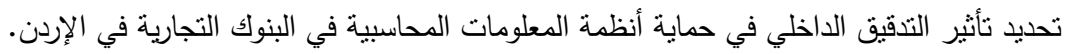

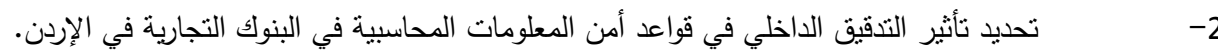

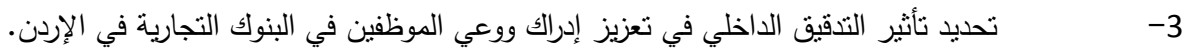

مشكلة الاراسة :-

تلعب أثز التدقيق الداخلي في حماية أنظمة المعلومات المحاسبية في البنوك التجارية في الإردن ، حيث

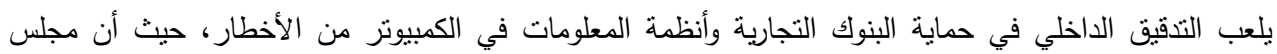

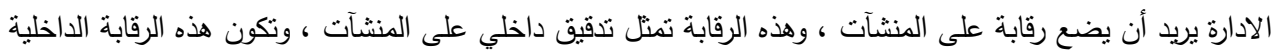

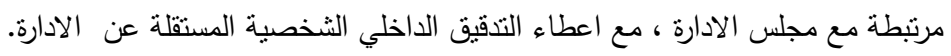

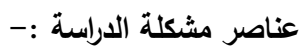

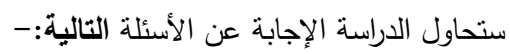

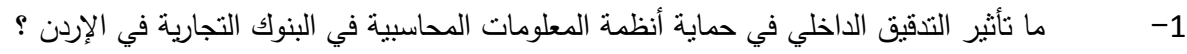

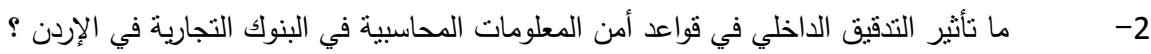

3- ما تأثثر التدقيق الداخلي في تعزيز إدراك ووعي الموظفين في البنوك التجارية في الإردن ؟

HO : ل اليوجد أثر ذو دلالة إحصائية لتأثير التدقيق الداخلي في حماية أنظمة المعلومات المحاسبية في البنوك التجارية في

الفرضية الثانية :-

HO : لا يوجد أثر ذو دلالة إحصائية لتأثير التدقيق الداخلي في قواعد أمن المعلومات المحاسبية في البنوك النجارية في الإردن.

الفرضية الثالثة :- الفحد

HO : ل ايوجد أثر ذو دلالة إحصائية لتأثير التدقيق الداخلي في تعزيز إدراك ووعي الموظفين في البنوك التجارية في الإردن.

أما متغيرات هذه الدراسة ، فيوجد أربعة متغيرات ، تتقسم إلى متغير مستقل واحد وثلاثة متغيرات تابعة ،

$$
\text { وتتمثل على النحو التالي :- }
$$

المتغير المستقل :- التدقيق الداخلي . المئل 
Journal of Business \& Management (COES\&RJ-JBM), 4(4), pp. 151-171

ب) (المتغيرات التابعة :- بتمنل في :-

حماية أنظمة المعلومات المحاسبية .

$-1$

قواعد أمن المعلومات المحاسبية . تونهات

تعزيز ادراك ووعي الموظفين .

\section{وفيما يلي نموذج لهذه الاراسة :-}

\section{نموذج الارراسة:-}

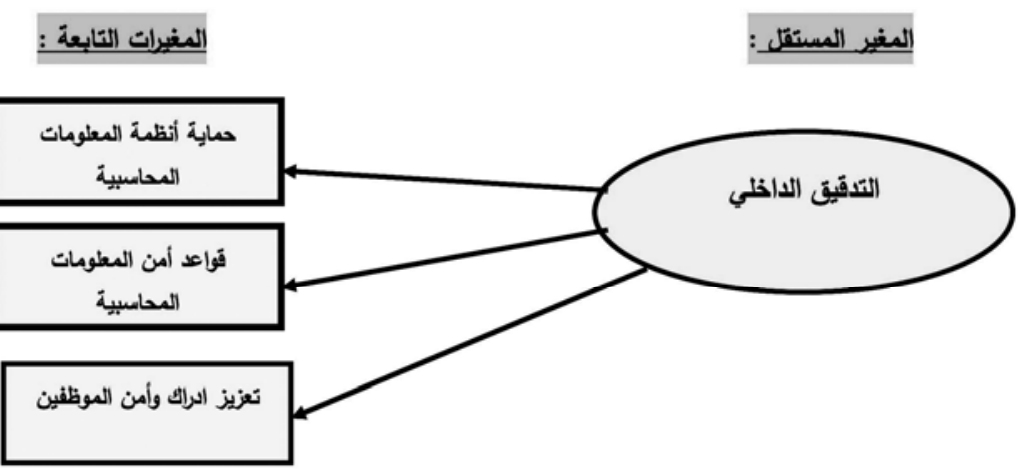

(The Impact of Information Systems Audit on Improving , دراسة (Harb) 2012) ، بعنوان

Bank's Performance).

هدفت دراسة (Harb) التي أجريت في الجامعة الإسلامية - غزة في فلسطين على التعرف على أثر ندقيق

نظم المعلومات في تحسين المصارف ، حيث يتمنل مجتمع الدراسة في المصارف العاملة في قطاع غزة والإدارات العامة لهذه المصارف ، فقد استخدم الباحث المنهج الوصفي التحليلي وتحليل الإنحدار ، واعتمد الباحث على عدد من في

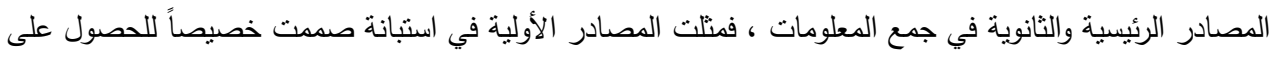

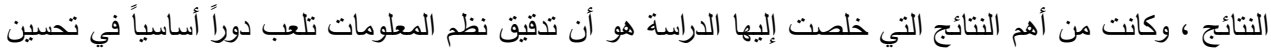
الأداء لاى الهصارف وتحقيق أهداف التتمية الإستراتيجية للمصارف، وذلك لأن المصارف لليها تكنولوجيا موثوق بها

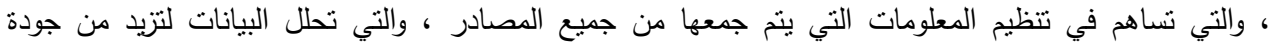

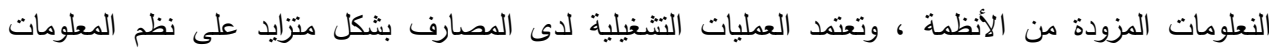

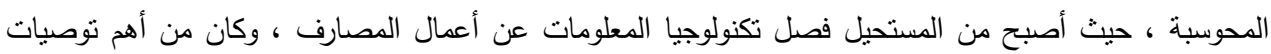
الباحث أن على المصارف الإهتمام أكثر بندريب الموظفين على استخدام تدقيق نظم المعلومات لديها ، وبالإضافة

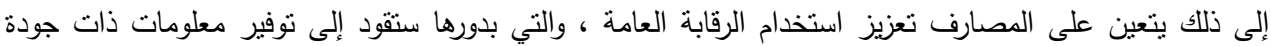
عالية خالية من الأخطاء والمخالفات. 
(Electronic Accounting in Efficiency Energy Sector , بعنوانة (1 ) 2012 (AL -Kasswna) دراسة (2012) under Conditions of Uncertainty - A Field Study Electricity Companies in the Hashemite Kingdom of Jordan).

أكدت دراسة ( AL -Kasswna) التي أجريت بجامعة (البلقاء التطبيقية) في الإردن على نقييم فعالية

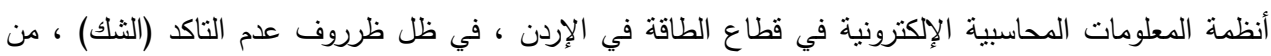

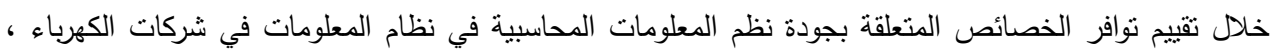

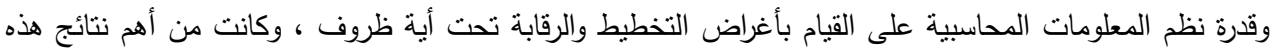

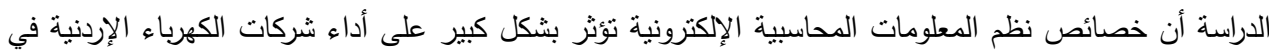

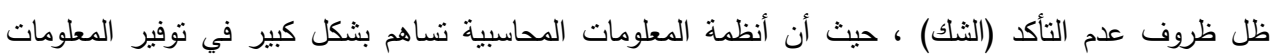
لأغراض التخطبط واتخاذ القرارات في ظل ظروف عدم التأكد (الثك).

(Role of Internal Audit Function in Promoting Effective , دراسة (Rotich) ، 2015) ، بعوان Corporate Governace of Commercial Banks in Kenya). اشارت دراسة (Rotich) إلى أنه يتم تصميم وظيفة التنقيق الداخلي للمساعدة في انتاج

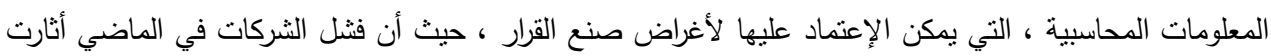

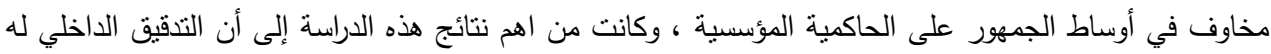

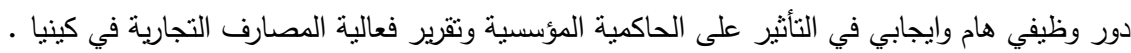

4) دراسة (الجويفل ، 2011) ، بعنوان ، " دور نظم المطومات المحاسبية المحوسبة في تحقيق فاعلية الرقابة الداخلية

$$
\text { في المصارف الإسلامية الإردنية ". }
$$

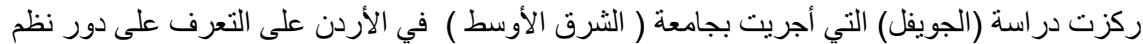

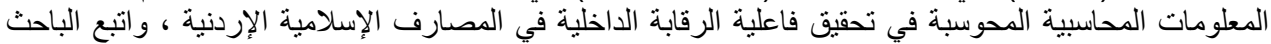

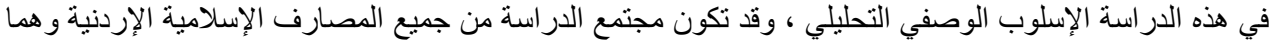

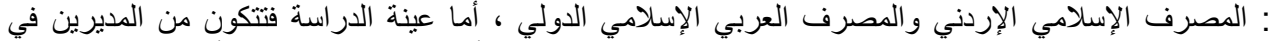

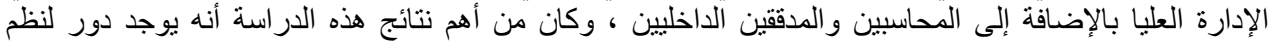

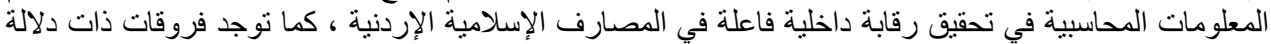

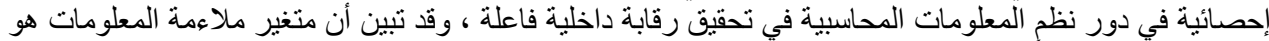

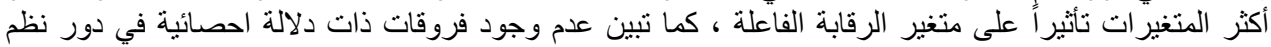
المعلومات المحاسبية في تحقيق رقابة فاعلة في الدصارف الإسلامية الإردنية.

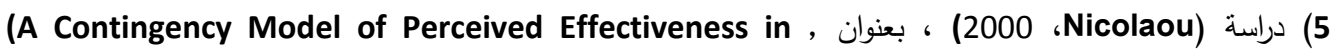
Accounting Information Systems : Organizational Coordination and Control Effect). هدفت دراسة (Nicolaou) إلى اختيار العلاقة بين تكامل النظم ودرجة نوافق تصميم نظم المعلومات

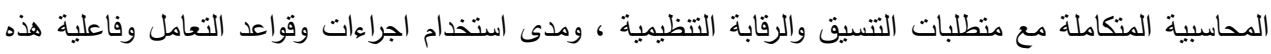
النظم ، والتي تقاس من خلال عاملين : الأساس يتمثل في رضا متخذي القرار عن دقة المعلومات الناتجة وفاعلية الرقابة عليها. 
6) ) دراسة (الصواف ، 2011) ، بعنوان ، " أثر الرقابة والتدقيق في تحجيم المخاطر التشغيلية في المصارف التجارية". هدفت دراسة (الصواف) إلى التأكيد على أهمية ودور الرقابة والتنقيق الداخلي في في حماية الدصارف

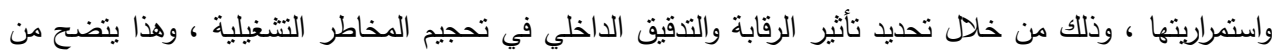

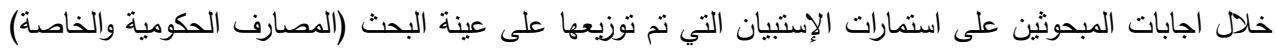

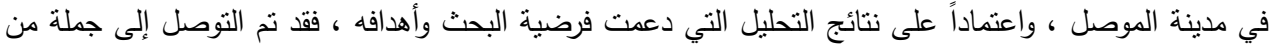

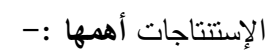

أ- اتفاق غالبية أفراد العينة على أهمية الرقابة والتدقيق الداخلي في تحجيم المخاطر التشغيلية .

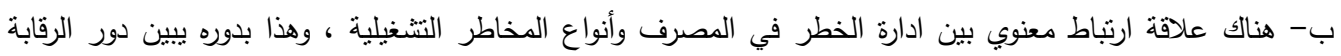
والندقيق الداخلي في دعم ادارة الخطر.

7) دراسة (العبيدي ، 2012) ، بعنوان ، " مخاطر استخدام نظم المعلومات المحاسبية المحوسبة وأثرها على فاعلية

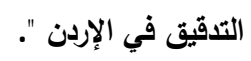

خلصت دراسة (العبيدي) والتي أجريت بجامعة (الثرق الأوسط) في الإردن ، إلى التعرف على مخاطر استخدام

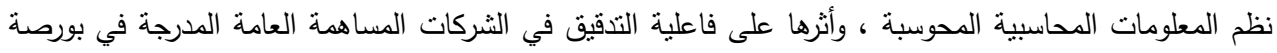

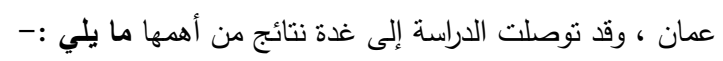

أ - وجود أثر ذو دلالة إحصائية للمخاطر البيئية الخاصة بنظم المعلومات المحاسبية المحوسبة على فاعلية عملية التدقيق الماتيق

في الثركات المساهمة العامة الإردنية.

ب - كثف عن وجود أثر لمخاطر ادخال نظم المعلومات ، تثغيل البيانات ، ومخرجات نظم المعلومات المحاسبية المحوسبة على فاعلية عملية التنقيق في الثركات المساهمة العامة الإردنية.

8) دراسة (نور وعدس ، 2007) ، بعنوان ، " مقاييس الرقابة والأمان للبيانات المحاسبية في ظل نظم المعلومات

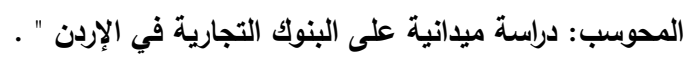

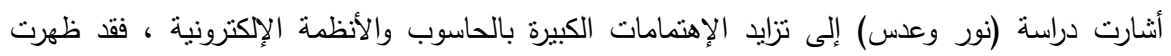

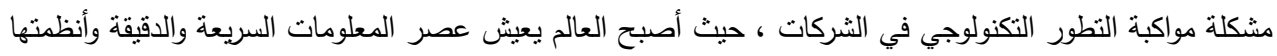

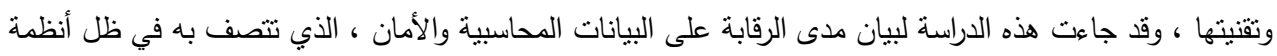

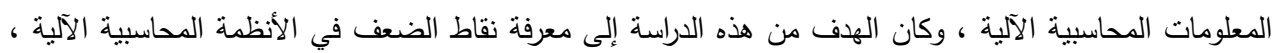

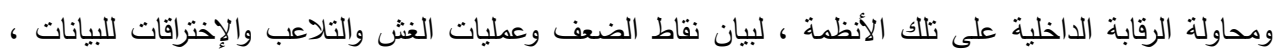

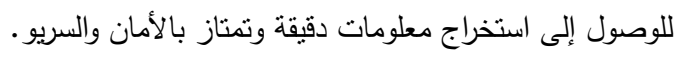

9) دراسة (القطناني ، 2004) ، بعنوان ، " أثر خصائص البيئة التقنية وتكنولوجيا المعلومات في مخاطر الرقابة التثغيلية

$$
\text { - دراسة تحليلية في المصارف الإردنية " . }
$$

هدفت دراسة (القطناني) إلى التعرف على بعض خصائله فيائص البيئة التقنية وتكنولوجيا المعلومات (الخصائص

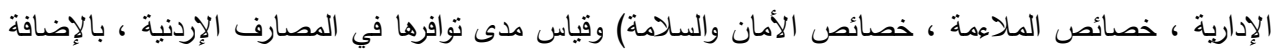

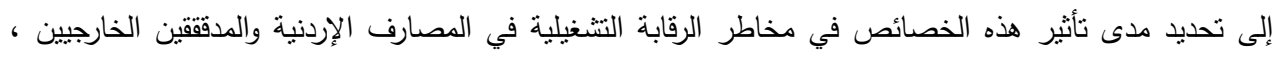


وكانت من أهم نتائج هذه الدراسة إلى أنه نوجد فروق ذات دلالة إحصائية بين المصارف الإردنية والمدققين الخرجيين

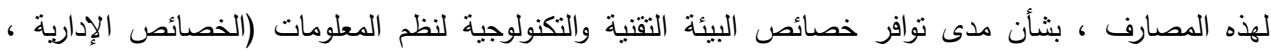
الملاءمة ، الأمن والسلامة) في المصارف الإردنية.

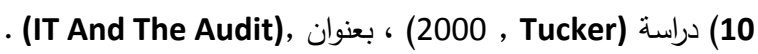

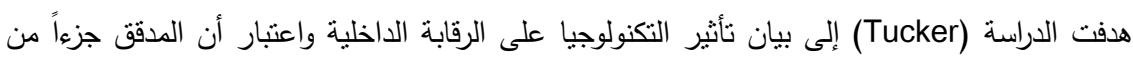

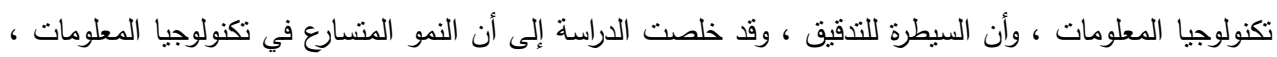

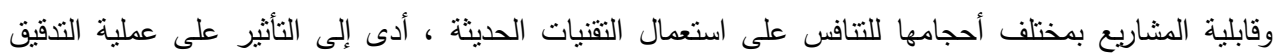

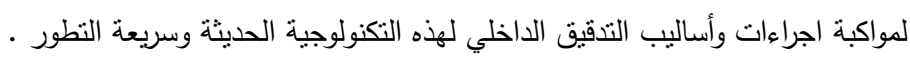

$$
\text { الإطار النظري للاراسة : }
$$

يعرف الباحث الرقابة الداخلية :- على أنها عبارة عن خطة تنظيمية تتكون من السياسات والاجراءات

$$
\text { للتأكد من :- }
$$

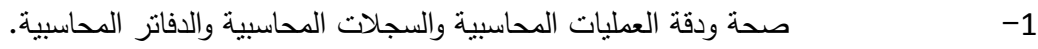

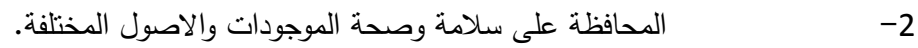

$$
\begin{aligned}
& \text { 3 - - متجيع الموظقين وتحسين الانتاجية. }
\end{aligned}
$$

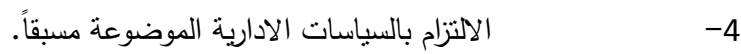

مما يعني ذللك أنه من الصفات العامة التي يجب أن يتصف بها المدقق الداخلي تتمثل بما يلي:-

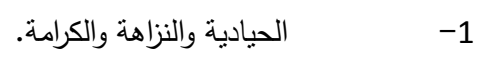

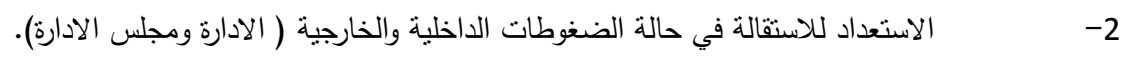

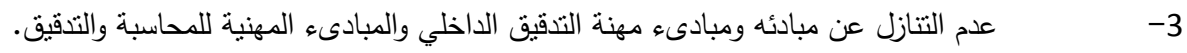

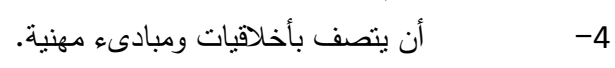

وعلى ضوء ذلك ترى أن أي نظام للمعلومات المحاسبية ، ينتج عنه بيانات محاسبية ، وهذه البيانات

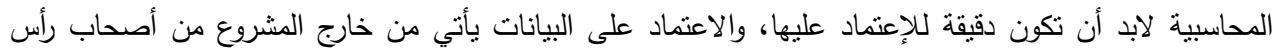

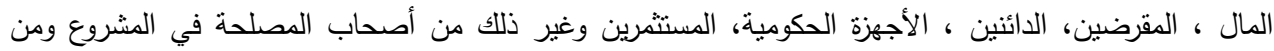
المجتمع بصورة عامة, ويتحقق هدف الدقة في هذه المعلومات المحاسبية بدرجة كبيرة من خلال وجود نظام قوي الإني لالرقابة الداخلية.

حيث يقول (الصحن وكامل ، 2000 ، ص3) أن المراجعة الداخلية تنضمن المقاييس التي تضمن لإدارة الوحدة تحقيق الأهداف التالية :-

$$
\text { ضماية موارد الوحدة ضد الاسراف والاختلاس. }
$$


Journal of Business \& Management (COES\&RJ-JBM), 4(4), pp. 151-171

$$
\begin{aligned}
& \text { ضمان دقة البيانات المحاسبية. } \\
& \text { تقويم مستوى الأداء (الكفاءة والفعالية). } \\
& \text { وأما أهداف الرقابة الداخلية فنتقسم إلى الأقسام التالية (عبداله ،2007 ، ص168):- }
\end{aligned}
$$

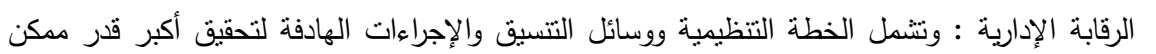

من الكفاية الإنتاجية مع تتجيع الإلتزام بالسياسات والقرارات الإدارية.

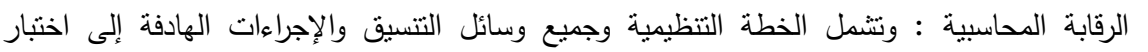

البيانات المحاسبية المثبتة في الدفاتر والحسابات ودرجة الإعنماد عليها.

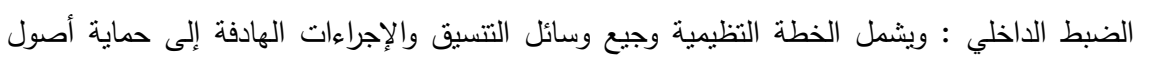

$$
\text { المشروع من الإختلاس والضياع أو سوء الإستعمال. }
$$

$$
\text { مقومات نظام التدقيق الداخي :- مقات }
$$

قسمت معايير التدقيق الدولية مقومات أو ركائز الرقابة الداخلية إلى خمسة مقومات أساسية هي (النتيبات،

البيئة الرقابية : وتتضمن وظائف الإدارة والمسؤولين عن التحكم الؤسسي ، بالإضافة إلى إتجاهاتهم

ومواقفهم وتصرفاتهم حيال الرقابة الداخلية للمنثأة وأهميتها.

الإجراءات الرقابية : وتتشمل مجموعة من الإجراءات الرقابية التي تساعد في تحقيق فاعلية بقية مكونات

$$
\begin{aligned}
& \text { الرقابة الإخرى ومن أهمها : } \\
& \text { أ ) مراجعة أو نقييم الأداء. } \\
& \text { ب ) معالجة البيانات. } \\
& \text { ج ) إجراءات الرقابة المالية. } \\
& \text { د ) فصل المهام. }
\end{aligned}
$$

3- تقييم المخاطر : وهو نثاط تقييمي تقوم به الإدارة ، حيث ينم تحديد وتحليل المخاطر ذات الصلة بإعداد البيانات

المالية بما يتفق مع المعايير المحاسبية.

4- - نظام المعلومات والتوصيل : ويشمل كافة نظم المعلومات.

5- الإثراف والتوجيه : ويشمل الإجراءات اللازمة لمتابعة نطبيق مختلف الجوانب الرقابية للتحقق من أنها تعمل حسب التب

خطط لها.

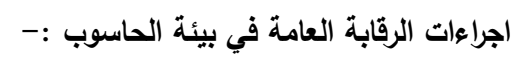

تعتبر إجراءات الرقابة العامة سياسات رقابية عريضة على مستوى إدارة الحاسوب وقابلة للنطبيق في أي نظام

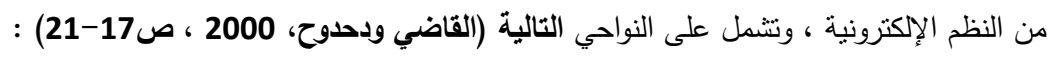

1- إدارة نظام المعلومات : يجب أن يشرف مدير نظم المعلومات على سير العمل في القسم.

2- تحليل النظم : هم المسؤولون عن تصميم نظام المعلومات. 
The Impact of Internal Audit in Protection of Accounting Information.

3- برمجة النطبيقات : هم من يقوموا بتصميم المخططات التذفقية لبرنامج الحاسوب الذي يتطلبه النظام.

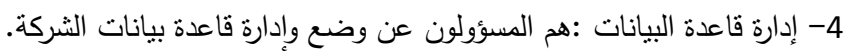
5- إدخال البيانات : هم المسؤولون عن ادخال الييانات وتحضير البيانتانت المدخلة للمعالجة والتأكد من صحتها. 6- تشغيل الحاسوب : يقوم مشغلوا الحاسوب بتثغيل ومراقبة أجهزة الحاسوب المركزية وفقاً لتعليمات معيارية. 7- رقابة البيانات : نقوم مجموعة رقابة البيانات في قسم نظم المعلومات بمراجعة واختبار جميع إجراءات إدخال البيانات والمراقبة والمعالجة والمراجعة. 8- الإتصالات البعدية : يتولى أخصائيو الإتصالات البعدية مسؤولية الحفاظ على شبكات الحاسوب. 9- برمجة النظم : هم المسؤولين عن نتبع مواضع الخلل في نظام التتغيل والتعامل مع برامج نطبيقات النظام.

ويرى الباحث أن المعلومات تعنبر أصل ذو قيمة مشتركة ، والذي يجب أن نتم حمايته بعناية واهتمام لأن

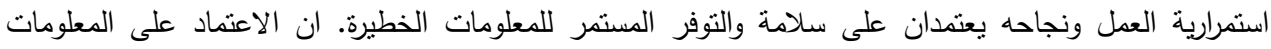

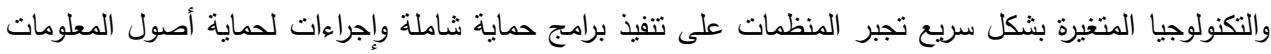

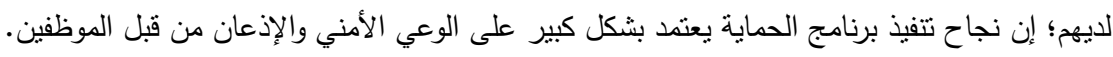

حيث أن المعلومات أصبحت بحد ذاتها من السلع أو المصادر الأكثر أهمية للعديد من المنظمات. الفثل في ضمان أمان المعلومات أو عدم توفرها للأشخاص اللذين بحاجة إليها، من الممكن وسوف يؤدي إلي خسارة مالية.

وخلا السنوات العديدة الماضية، التغيرات في التكنولوجيا جعلت من استخدام الكمبيوتر أكثر سهولة للاستخدام. ومع ذللك، قام مستخدمو النظام المسالمون بإنشاء مهام محددة متعلقة بتأمين الأمان والسلامة لأنظمة فئنة الاتصال والكمبيوتز ، معلومات الإدارة والبيانات.

ويرى الباحث أنه وبالرغم من أن الكمبيوتر يقوم بالتزويد بفوائد عديدة ، إلا إنه من النادر أن تقوم الإدراة

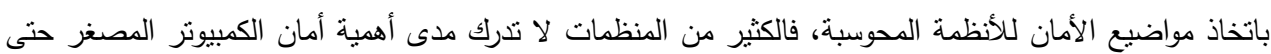

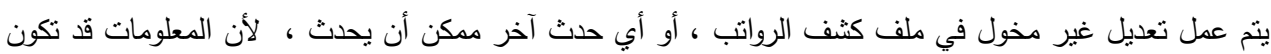

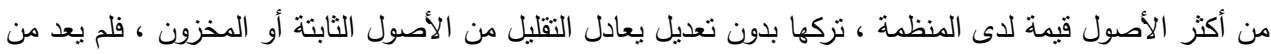

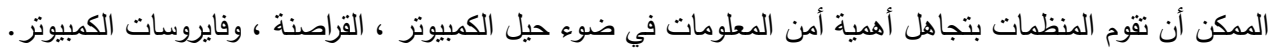

ويرى الباحث أيضاً أن جريمة الكمبيوتر تكاد تكون أمر حتمي في أية منظمة إلا في حال اتخاذ اجراءات

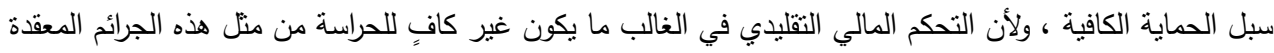

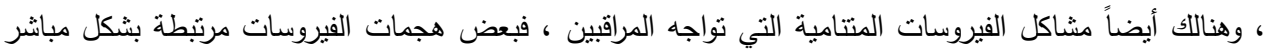

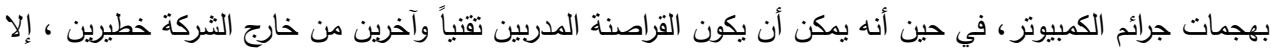

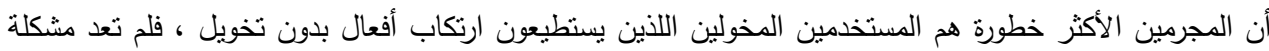

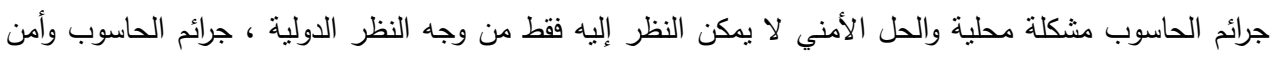

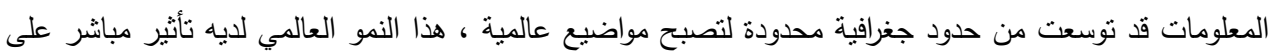

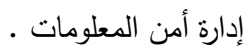


المنهج والإجراءات :

أ) مجتمع الاراسة: :- الاجراعة :

ينكون مجتمع الدراسة من جميع البنوك التجارية العاملة في الإردن مع نهاية عام 2015 ، والمنحصرة في

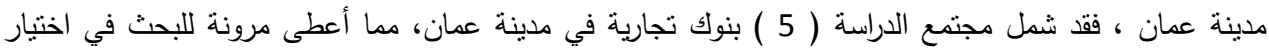
العينة (عينة الدراسة). وأن وحدة التحليل هم الأفراد العاملين في البنوك التجارية (وعددهم 100 ، ( N = 100 ()).

$$
\begin{aligned}
& \text { ب) عينة الدراسة: :- } \\
& \text { تم اختيار عينة الدراسة بناءً على الثروط التالية :- } \\
& \text { - - - أن أنكون اردنية الجنسية. } \\
& \text {-2 - أن تكون بنوك تجارية . } \\
& \text { 3- أن يكون فرع رئيس اللبنك. } \\
& \text { 4- - أن تكون في محافظة عمان. } \\
& \text { 5- وقد اثتملت العينة العشوائية البسيطة لمجتمع الدراسة على (5) بنوك تجارية، انحصرت في :- } \\
& \text { 1- - 1 - البناك العربي. }
\end{aligned}
$$

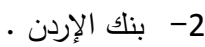

$$
\begin{aligned}
& \text { 3- البنك الإهلي الإردني · } \\
& \text { 4- بنك الإنكان للتجارة والتمويل . } \\
& \text { بنك الإستثمار العربي الإردني. }
\end{aligned}
$$

وسوف يتم توزيع الاستبانات على الأفراد العاملين في البنوك التجارية ، المنحصرين في مدراء ورؤساء

أقسام البنك وعلى الديرين ورؤساء أقسام المحاسبة ، ويرجع السبب في إختيار هؤلاء إلى اعتقاد الباحث بأن تلآك الفئة

من العاملين هي الجهة المعنية في موضوع الدراسة ، لذللك سوف يتم توزيع الاستبانات على الفئات التالية :-

$$
\begin{aligned}
& \text { 1 }
\end{aligned}
$$

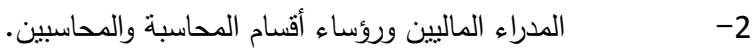

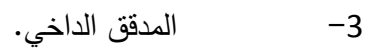

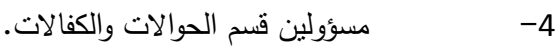

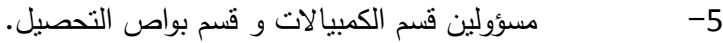

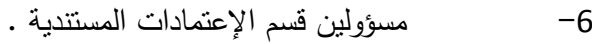

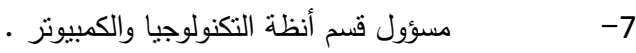

وسيتم استخدام العينة العشوائية البسيطة ، ومن ومن خلا تلك المجوعة المختارة من العينة التي تثكل

عينة الدراسة ، فسيتم توزيع ( 100 ) استبانة على الأفراد العاملين في البنوك التجارية ـ أما بالنسبة للفترة الزمنية

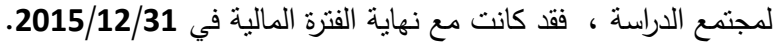


ج) نوع الدراسة:- هذه الدراسة وصفية تحليلية وميدانية، لأنها تختبر وتحلل وتصف أثر التدقيق الداخلي في حماية أنظمة المعلومات المحاسبية في البنوك التجارية في الإردن.

$$
\begin{aligned}
& \text { محدات الدراسة :- - م } \\
& \text { وتتمثل محددات الدراسة في :- } \\
& \text { 1- حجم العينة المختارة عبارة عن عينة عشوائية بسيطة ضمن شروط محددة لإختيار العينة. }
\end{aligned}
$$

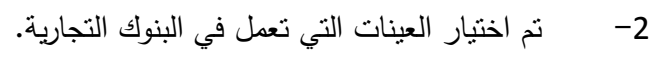

$$
\begin{aligned}
& \text { 3- انسجام جميع البنوك التجارية . } \\
& \text { خصائص عينة الاراسة :- } \\
& \text { تشمل العينة الخصائص التالية :- }
\end{aligned}
$$

جنسية الثركة ، طبيعة النشاط الممارس والفترة الزمنية لعينة الدراسة ، وتاريخ التأسيس لكل بنك لغاية

$$
\text { أ) جنسية الشركة: :- جميع البنوك التجارية المدروسة أردنية الجنسية. }
$$

ب) طيعة نشاط البنك التجاري الممارس:- جميعها ذات أنشطة متثابه في أعمال البنوك التجارية في الإردن.

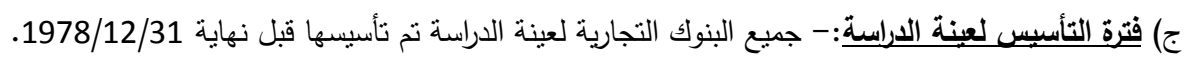
د) الفترة الزمنية لعينة الدراسة:- نم دراسة عينة الدراسة لغاية نهاية 2015/12/31.

تم جمع البيانات من مصادر ثانوية وأولية والخبرة الثخصية لدى الباحث في قطاع البنوك ، كما يلي:-

$$
\text { أ) المصادر الثانوية ، وتتكون من :- }
$$

المعلومات الجاهزة والمتوفرة في المكتبات من كتب ومراجع ودوريات ومقالات تدور حول موضوع الدراسة ،

$$
\text { ودراسات سابقة ، وقد تم الإعتماد عليها في تحديد الإطار النظري للاراسة. }
$$

\begin{tabular}{|c|c|}
\hline 100 & عدد الاستبانات الموزعة ( لاى الباحث ) \\
\hline 88 & عدد الاجابات عن الاستبانات (لدى الباحث ) = \\
\hline$=$ & ل انات الني لم يستجيب عليه \\
\hline
\end{tabular}

$$
\text { التقارير السنوية الصادرة عن البنوك التجارية. }
$$

ب) المصادر الأولية :- وتتمثل في استبانة يتم توزيعها على الأفراد العاملين في البنوك التجارية المتمنلين في عينة

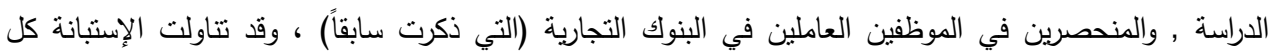
أهداف البحث والتي نت تصميمها في ضوء البيانات الثانوية ـ لذلك سوف يتم توزيع ( 100 ) استبانة على الأفراد

$$
\text { العاملين في البنوك التجارية. }
$$




\section{ويتضح أن النسبة المئوية للاستجابة نساوي (88 ٪ 100 = 88 \%) .}

$$
\text { الأساليب الإحصائية :- }
$$

لتحليل بيانات الدراسة ، اعتمد الباحث الأساليب الإحصائية والمؤشرات القياسية ، وأهم الأساليب

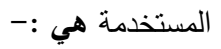

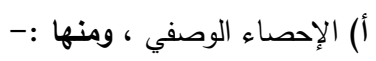

$$
\text { 2 } \quad \text { - } \quad \text { - } 1
$$

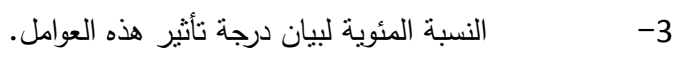

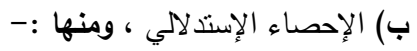$$
\text { T- إختبار }
$$$$
\text { . - م الإنحدار المتعدد - }
$$

$$
\text { ملاحظة :- سيتم استخدم ( SPSS ) لتحليل البيانات :- SPSS) }
$$

(Statistical Package for Social Sciences, SPSS) .

\begin{tabular}{|c|c|c|c|}
\hline كرونباخ & عدد الفقرات & المجال & 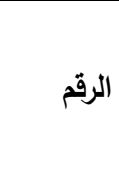 \\
\hline 0.772 & 7 & التدقيق الداخلي (المتغير المستقل) & 1 \\
\hline 0.896 & 7 & حماية أنظمة المطلومات المحاسبية (المتغير التابع الأول) & 2 \\
\hline 0.712 & 7 & قواعد أمن المطومات (المتغير التابع الثاني) & 3 \\
\hline 0.751 & 7 & تعزيز ادراك ووعي الموظقين (المتغير التابع الثالث) & 4 \\
\hline 0.904 & 28 & 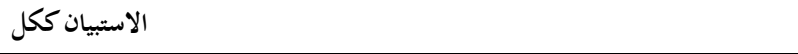 & \\
\hline
\end{tabular}

$$
\text { اختبار فرضيات للاراسة :- }
$$

يمثل هذا الجزء من الاراسة تحليل المتغيرات المستقلة والتابعة واختبار الفرضيات وذلك على النحو

$$
\text { التالي:- }
$$

يمثل جدول (5-1) نتائج ثبات مجال الإفصاح المحاسبي ومجالات المستثرين الجدد في البيئة التنافسية

$$
\text { بإسلوب ( ألفا كرونباخ ) للإتساق الداخلي:- نباتب لبات }
$$

تثبير نتائج الجدول رقم (5-1) إلى أن قيمة كرونباخ ألفا قد بلغت (0.772) للتنقيق الداخلي للمتغير المستقل ، وبلغت (0.896) لحماية أنظمة المعلومات المحاسبية للمتغير التابع الأول ، وبلغت (0.712) لقواعد أمن 
المعلومات للمتغير التابع الثاني ، وبلغت (0.751) لتعزيز ادراك ووعي الموظفين للمتغير التابع الثالث ، كما بلغت

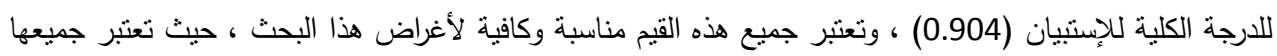
مرتفعة لأنها قريبة من واحد صحيح والتي تعتبر أكبر قيمة قد يصلها التبات.

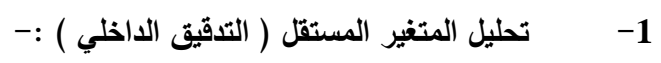

قام الباحث بالتحليل الباحث بإيجاد قيم المتوسطات الحسابية والإنحرافات المعيارية والأهمية النسبية لكل

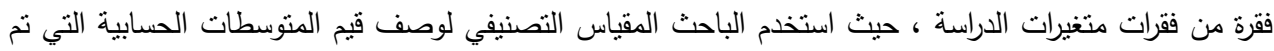

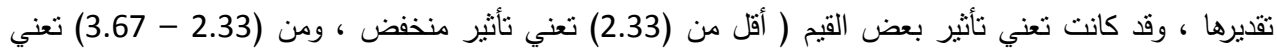
تأثثر منوسط ، ومن (3.67 - 5.00) تعني تأثثر مرتفع ).

جدول رقم (5-2) للمتوسطات الحسايية والإنحرافات المعيارية لفقرات المتغير المستقل ( التدقيق الداخلي ) مرتبة ترتيباً تنتازلياً على النحو التالي:-

\begin{tabular}{|c|c|c|c|c|c|c|}
\hline 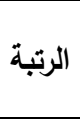 & 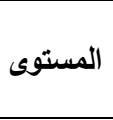 & الألهية & 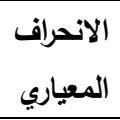 & الحستوسط & 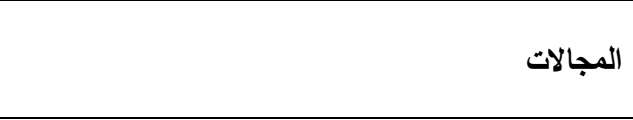 & قالم \\
\hline 1 & متوسط & 72.8 & 1.14 & 3.64 & إلى أي مدى يتوفر في البنك قسم للتنقيق الداخلي & 1 \\
\hline 2 & متوبط & 72.4 & 1.20 & 3.62 & 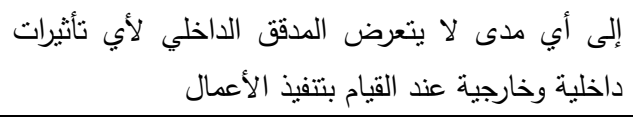 & 4 \\
\hline 2 & متوسط & 72.4 & 1.22 & 3.62 & الداخلى أي مدى يهتم المدقق الداخلي بتطبيق معايير التدقيق & 6 \\
\hline 4 & متوسط & 68.0 & 1.25 & 3.40 & تحيز وتعارض أبي مدى يؤدي المدقق الداخلي الأعمال بنزاهة بدون & 5 \\
\hline 5 & متوسط & 66.4 & 1.33 & 3.32 & الداخلى أي مدى تهنم الإدارة بإجراءات وأنظمة التدقيق & 2 \\
\hline 6 & متوسط & 62.2 & 1.34 & 3.11 & إلى أي مدى يتم تجهيز تقارير دورية للإدارة & 3 \\
\hline 7 & متوسط & 60.8 & 1.21 & 3.04 & إلى أي مدى يهتم المدقق الداخلي بالحاكمية المؤسسية & 7 \\
\hline & متوسط & 67.8 & 0.81 & 3.39 & التدقيق الداخلي & \\
\hline
\end{tabular}

يلاحظ من الجدول رقم (5-3) أن مستوى التدقيق الداخلي (المتغير المستقل) كان متوسطاً ، إذ بلغت قيمة المتوسط الحسابي (3.39) بأهمية نسبية مقدارها (67.8) ، وجاء مستوى فقرات المتغير منوسطاً، إذ نزاوحت

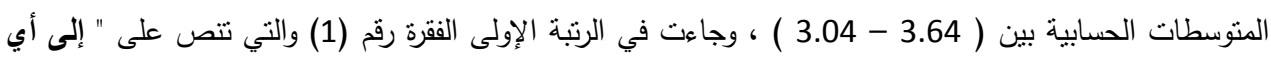
مدى يتوفر في البنك قسم للتدقيق الداخلي " ، بمنتسط حسابي مقداره (3.64) وبأهمية نسبية مقدارها (72.8) ، 
وجاءت الفقرة رقم (7) والتي تتص على " إلى أي مدى يهتم المدقق الداخلي بالحاكمية المؤسسية "، بمتوسط حسابي مقداره (3.04) وبأهمية نسبية مقدارها (60.8).

2- - تحليل المتفير التابع الأول ( حماية أنظمة المعلومات المحاسبية ):-

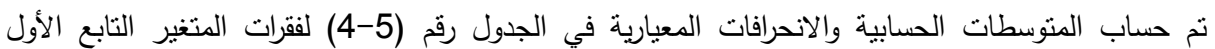

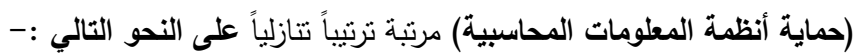

\begin{tabular}{|c|c|c|c|c|c|c|}
\hline الرتبة - ابة & 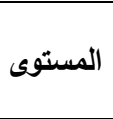 & الأهمية & 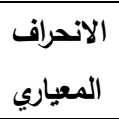 & الحستوسط & 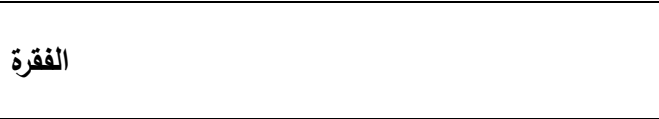 & قالر \\
\hline 1 & 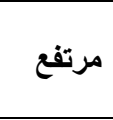 & 74.0 & 1.21 & 3.70 & إلى أي مدى يحقق الأنظمة الحاسوبية كفاءة عالية في & 6 \\
\hline 2 & متوسط & 69.6 & 1.28 & 3.48 & 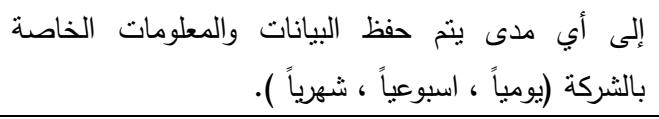 & 3 \\
\hline 3 & متوسط & 67.2 & 1.32 & 3.36 & إلى أي مدى ينم وضع قيود على تعديل المعلومات & 4 \\
\hline 4 & متوسط & 66.0 & 1.09 & 3.30 & بأنظى أي مدى يضع البنانك نظام للحماية من التلاعب والغش & 5 \\
\hline 5 & متوسط & 62.6 & 1.26 & 3.13 & إلى أي مدى يستخدم الموظف كلمة السر للجهاز الخاص & 1 \\
\hline 6 & متوسط & 61.6 & 1.07 & 3.08 & بسرعة عالية من قبل مستخ الرجدم إلى المعلومات المعات عند الحاجة إليها & 7 \\
\hline 7 & متوسط & 61.4 & 1.33 & 3.07 & مستخدم أنظمة مدى يتم ادخال المعلومات الخاصة بالموظف & 2 \\
\hline & متوسط & 66.0 & 0.96 & 3.30 & حماية أنظمة المعلومات المحاسبية & \\
\hline
\end{tabular}

يلاحظ من الجدول (5-4) أن مستوى المتغير التابع الأول (حماية أنظمة المعلومات المحاسبية) كان

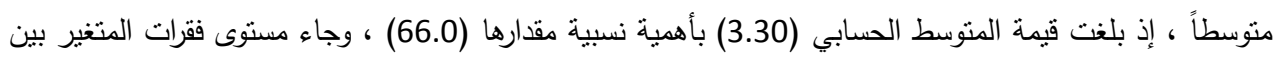

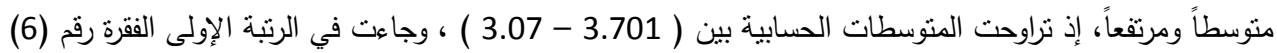
والتي تتص على " إلى أي مدى يحقق الأنظمة الحاسوبية كفاءة عالية في تخزين المعلومات بقدرة استيعابية عالية

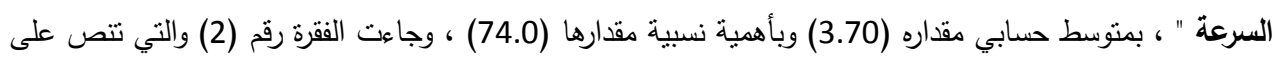

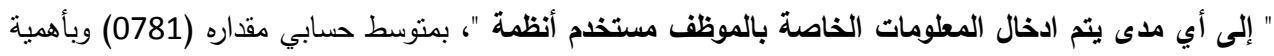
نسبية مقدارها (61.4). 3- - تحليل المتغير التابع الثاني ( قواعد أمن المعلومات ):يبين الجدول رقم (5-5) المتوسطات الحسابية والانحرافات المعيارية لفقرات المتغير التابع الثاني (قواعد أمن

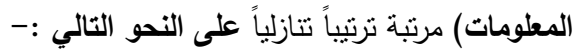


The Impact of Internal Audit in Protection of Accounting Information........

\begin{tabular}{|c|c|c|c|c|c|c|}
\hline 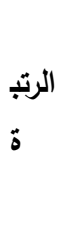 & المستو & $\begin{array}{l}\text { الأهمي } \\
\text { النسبي } \\
\text { الن }\end{array}$ & الانحرا & 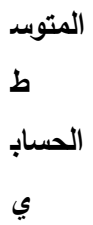 & 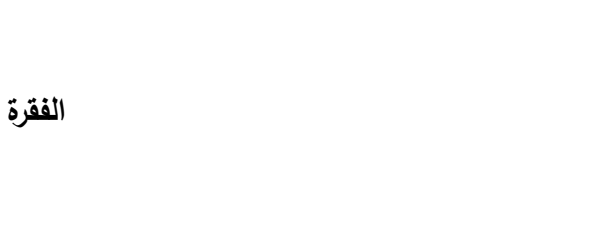 & قالر \\
\hline 1 & متوسط & 72.6 & 0.88 & 3.63 & 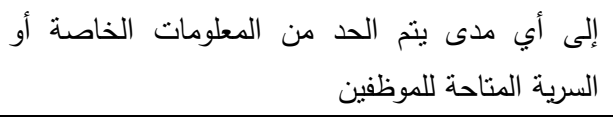 & 5 \\
\hline 2 & متوسط & 70.8 & 1.14 & 3.54 & 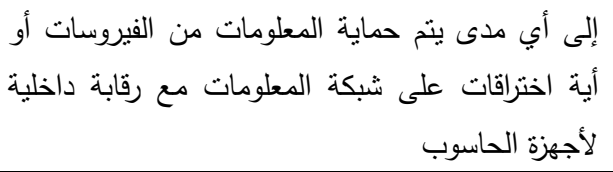 & 6 \\
\hline 3 & متوسط & 69.2 & 1.09 & 3.46 & الحصى أي مدى يستخدم البنك خطة للطوارئ الإحتمالية & 7 \\
\hline 4 & متوسط & 65.6 & 1.31 & 3.28 & إلى أي مدى يتم ضبط عملية الدخول إلى المعلومات & 2 \\
\hline 5 & متوسط & 64.0 & 1.35 & 3.20 & المى أبي مدى ينم عملية توفير المعلومات العامة عن & 3 \\
\hline 6 & متوسط & 62.4 & 1.35 & 3.12 & 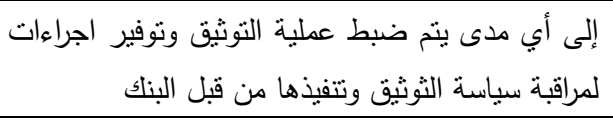 & 1 \\
\hline 7 & متوسط & 60.8 & 1.30 & 3.04 & 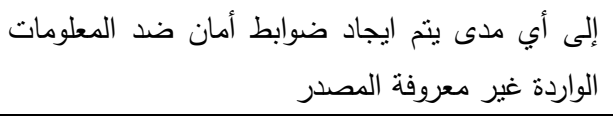 & 4 \\
\hline & متوسط & 66.6 & 0.74 & 3.33 & قواعد أمن المعلومات & \\
\hline
\end{tabular}

يلاحظ من الجدول (5-5) أن مستوى المتغير النابع الثاني (قوعد أمن المعلومات) كان متوسطاً ، إذ إذ بلغت قيمة المتوسط الحسابي (3.33) بأهمية نسبية مقدارها (66.6) ، وجاء ماءئ مستوى فقرات المتغير بين متوسطاً

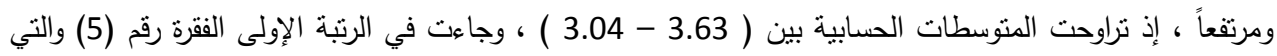

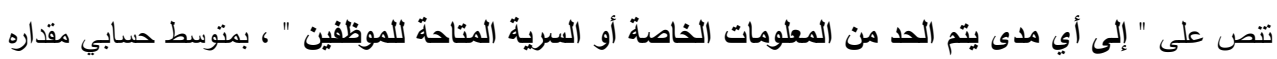

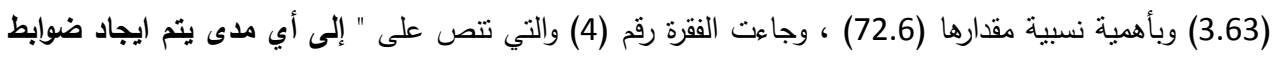
أمان ضد المعلومات الواردة غير معروفة المصدر "، بمتوسط حسابي مقداره (3.04) وبأهمية نسبية مقدارها (60.8).

4- تحليل المتغير التابع الثالث ( تعزيز ادرالك ووعي الموظفين ):يبين الجدول رقم (5-6) المتوسطات الحسابية والانحرافات المعيارية لفقرات المتغير التابع الثاني (قواعد أمن أنمات

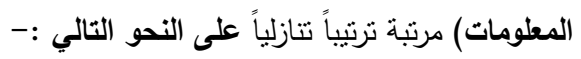


Journal of Business \& Management (COES\&RJ-JBM), 4(4), pp. 151-171

\begin{tabular}{|c|c|c|c|c|c|c|}
\hline 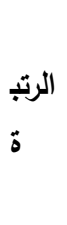 & المستو & $\begin{array}{l}\text { الأهمب } \\
\text { النسبي } \\
\text { الن }\end{array}$ & المعياري & المتوسد & الفقرة & 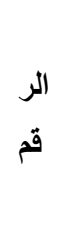 \\
\hline 1 & 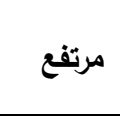 & 75.4 & 1.15 & 3.77 & 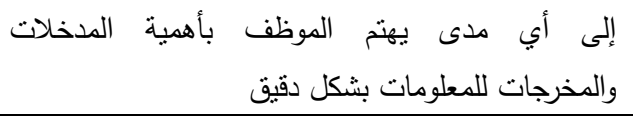 & 6 \\
\hline 2 & 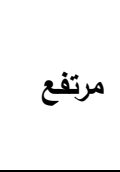 & 73.6 & 1.18 & 3.68 & إلى أي مدى يدرك الموظف داخل البنلك بأهمية الحماية & 4 \\
\hline 3 & متوسط & 70.6 & 1.12 & 3.53 & البنى أبي مدى هناك وعية وسرية المعلومات داخراك من الكمبيوتر الموظفين داخل & 1 \\
\hline 4 & متوسط & 68.4 & 1.18 & 3.42 & المعلى أي مدى ينت تأهيل الموظفين تأهيلاً علمياً بالإنظمة & 5 \\
\hline 5 & متوسط & 65.4 & 1.30 & 3.27 & مع المدقى الدي مدى هنالك تعاون من قبل الموظفين داخل البنك & 2 \\
\hline 6 & متوسط & 64.8 & 1.21 & 3.24 & 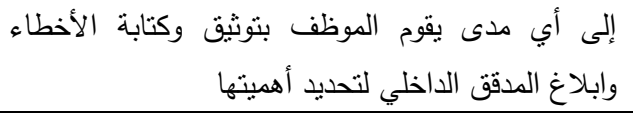 & 7 \\
\hline 7 & متوسط & 63.8 & 1.35 & 3.19 & 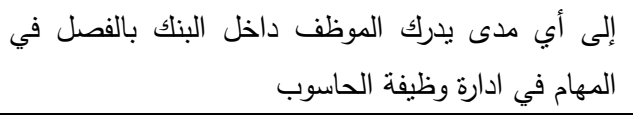 & 3 \\
\hline & متوسط & 68.8 & 0.77 & 3.44 & تعزيز ادراك ووعي الموظقين & \\
\hline
\end{tabular}

يلاحظ من الجدول (5-6) أن مستوى المتغير التابع الثالث (تعزيز ادراك ووعي الموظفين) كان متوسطاً ،

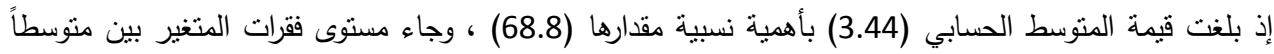

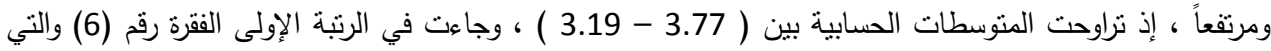
تتص على " إلى أي مدى يهتم الموظف بأهمية المدخلات والمخرجات للمعلومات بثكل دقيق " ، بمتوسط حسابي

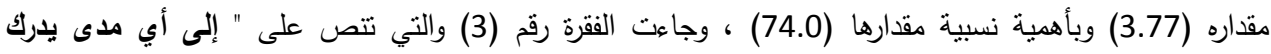

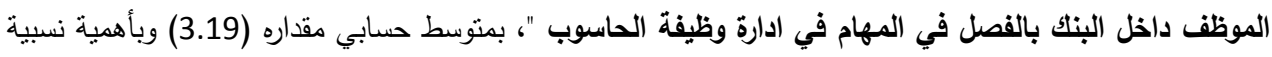
مقدارها (63.8).

$$
\begin{aligned}
& \text { ثانياً :- اختبار فرضيات الاراسة :- } \\
& \text { الفرضية الإولى :- }
\end{aligned}
$$

HO : ل ايوجد أثر ذو دلالة إحصائية لتأثير التدقيق الداخلي في حماية أنظمة المعلومات المحاسبية في البنوك التجارية في الإردن. - الإن. 
لإختبار هذه الفرضية فقد نم استخدام تحليل الإنحدار البسيط ، ويوضح جدول (5-7) نتائج تحليل الإنحدار الخطي البسيط ، أثز النذقي الداخلي في حماية أنظمة المعلومات المحاسبية في البنوك التجارية في الإردن

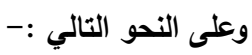

\begin{tabular}{|c|c|c|c|c|c|c|c|c|}
\hline Sig $t$ & $\mathbf{t}$ & $\boldsymbol{\beta}$ & $\beta_{0}$ & Sig $f$ & $f$ & $\mathbf{R}^{2}$ & $r$ & المتغير المستقل \\
\hline$* 0.000$ & 8.23 & 0.780 & 0.657 & $* 0.000$ & 67.85 & 0.427 & 0.654 & التدقيق الداخلي \\
\hline
\end{tabular}

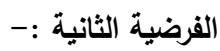

HO : ل الاوجد أثر ذو دلالة إحصائية لثأثير التدقيق الداخلي في قواعد أمن المعلومات المحاسبية في البنوك التجارية في الإردن.

لإختبار هذه الفرضية فقد نم استخدام تحليل الإنحدار البسيط ، ويوضح جدول (5-8) نتائج تحليل الإنحدار الخطي البسيط ، أثز الندقي الداخلي في تعزيز إدراك ووعي الموظفين في البنوك التجارية في الإردن وعلى الإنى

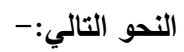

\begin{tabular}{|c|c|c|c|c|c|c|c|c|}
\hline Sig $t$ & $\mathbf{t}$ & $\beta$ & $\beta_{0}$ & Sig $f$ & $f$ & $\mathbf{R}^{2}$ & $\mathbf{r}$ & المتغير المستقل \\
\hline$* 0.000$ & 7.75 & 0.574 & 1.378 & $* 0.000$ & 60.09 & 0.398 & 0.631 & التدقيق الداخلي \\
\hline
\end{tabular}

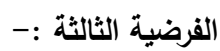

HO : لا يوجد أثر ذو دلالة إحصائية لتأثير التدقيق الداخلي في تعزيز إدراك ووعي الموظفين في البنوك التجارية في الإردن.

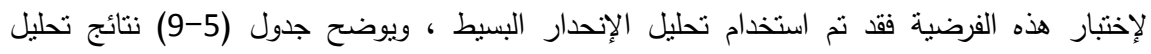
الإنحدار الخطي البسيط ، أثز الندقي الداخلي في تعزيز إدراك ووعي الموظفين في البنوك التجارية في الإردن وعلى الإنى

$$
\text { النحو التالي:- }
$$

\begin{tabular}{|c|c|c|c|c|c|c|c|c|}
\hline Sig $t$ & $t$ & $\beta$ & $\beta_{0}$ & Sig $f$ & $f$ & $\mathbf{R}^{2}$ & $r$ & المتغير المستقل \\
\hline$* 0.000$ & 4.12 & 0.378 & 2.159 & $* 0.000$ & 17.05 & 0.158 & 0.397 & التدقيق الداخلي \\
\hline
\end{tabular}

النتائج والتوصيات :

$$
\text { النتائج :- }
$$

بعد تحليل نتائج بيانات عينة الدراسة واختبار فرضيات الدراسة ، يمكن تلخيص نتائج الدراسة على النحو

$$
\text { الاتي :- }
$$

يوجد تأثثر ذات دلالة إحصائية (للفرضية الأولى) لتأثير التدقيق الداخلي في حماية أنظمة المعلومات المحاسبية $-1$

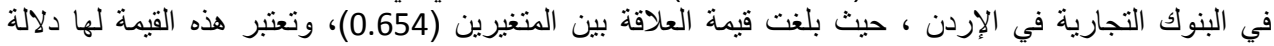

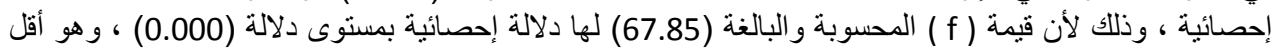
من (5\%)، وتثير هذه النتيجة إلى أثر التدقيق الداخلي في حماية أنظمة المعلومات المحاسبية في البنوك التجارية في وهائ 


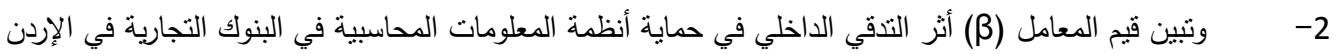

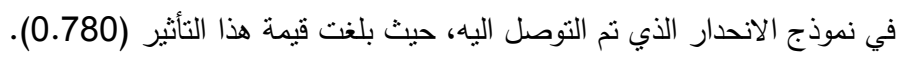

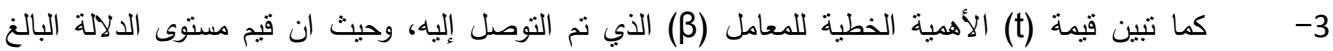

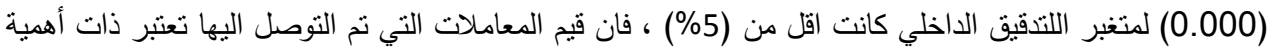

في نموذج الانحدار.

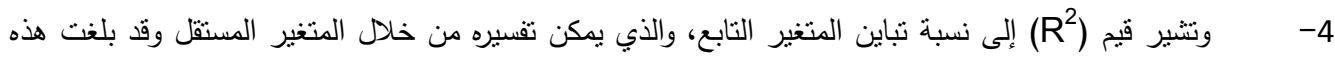

النسبة (42.7 \%) ، وتبين هذه النسبة ددى قدرة المتغير المستقل في التنبؤ بالمتغير التابع.

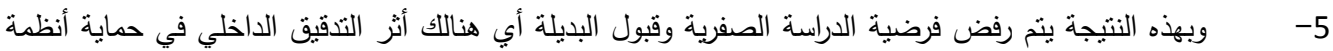

المعلومات المحاسبية في البنوك التجارية في الإردن.

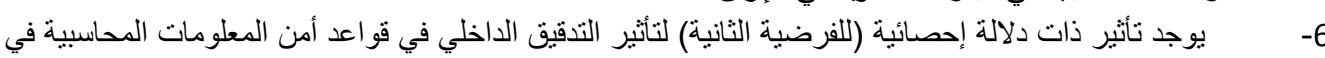

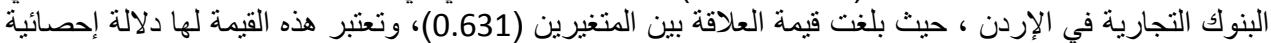

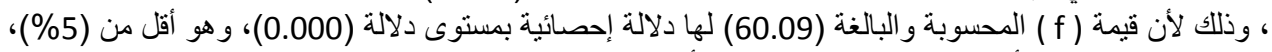

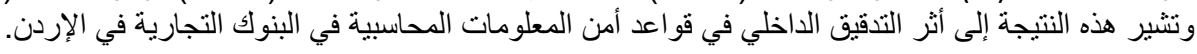

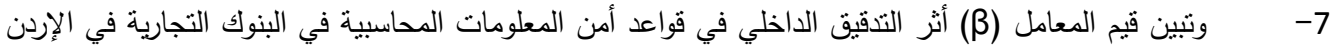

في نموذج الانحدار الذي تم النوصل اليه، حيث بلغت قيمة هذا التأثير (0.574).

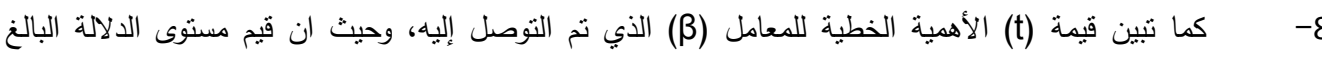

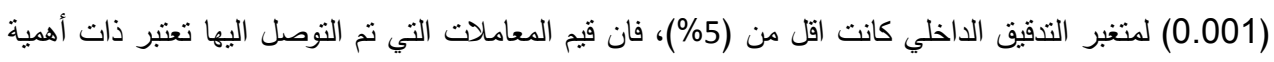

في نموذج الاتحدار.

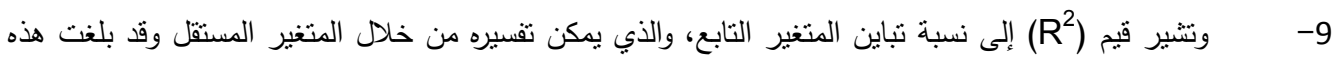

النسبة (39.8 \%) ، وتبين هذه النسبة مدى قدرة المتغير المستقل في التنبؤ بالمتغير التابع.

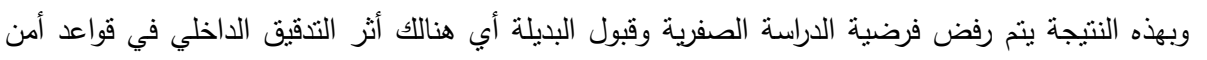

المعلومات المحاسبية في البنوك التجارية في الإردن.

يوجد نأثير ذات دلالة إحصائية (للفرضية الثالثة) لتأثير التدقيق الداخلي في تعزيز إدراك ووعي الموظفين في

البنوك التجارية في الإردن ، حيث بلغت قيمة العلاقة بين المتغيرين (0.397)، وتعتبر هذه القيمة لها دلالة إحصائية

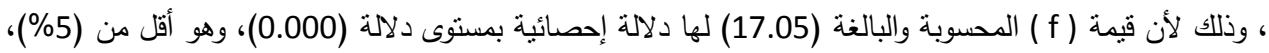

وتثير هذه النتيجة إلى أثر التدقيق الداخلي في تعزيز إدراك والكي والثي الموظفين في البنوك التجارية في الإردن.

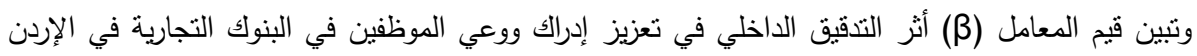

في نموذج الانحدار الذي تم التوصل اليه، حيث بلغت قيمة هذا التأثير (0.378).

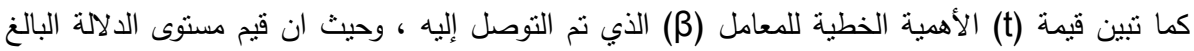

(0.001) لمتغبر التدقيق الداخلي كانت اقل من (5\%)، فان قيم المعاملات التي نم التوصل اليها تعتبر ذات أهمية

$$
\text { في نموذج الانحدار. }
$$

وتثير قيم (R2) إلى نسبة تباين المتغير التابع ، والذي يمكن تفسيره من خلال المتغير المستقل وقد بلغت هذه

النسبة (15.8 ٪) ، وتبين هذه النسبة ددى قدرة المتغير المستقل في التنبؤ بالمتغير التابع.

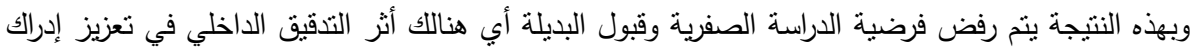


بعد تحليل فرضيات الدراسة المتعلقة أثر أثر الندقي الداخلي في حماية أنظمة المعلومات المحاسبية في

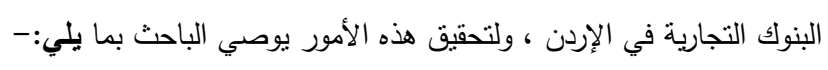

النتائج ايجابية يفترض تعزيزها للمحافظة على أنظمة المعلومات المحاسبية في البنوك التجارية زيادة الإهتمام

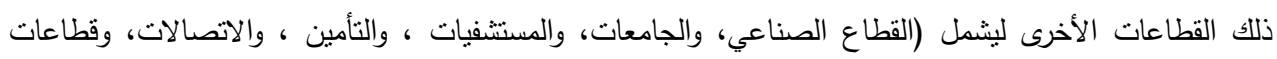
4- - أظرى). في اللبنوك التجارية.

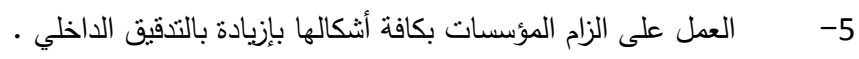

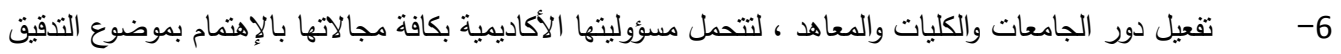

1- الجويفل ، أحمد سلامة سليمان ، 2011 ، " دور نظم المعلومات المحاسية المحوسبة في تحقيق فاعلية الرقابة

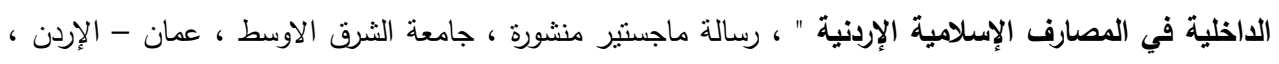
.(on-line)-(http://www.google.com 2- الدنيبات ، علي عبد القادر ، 2012 ، " تدقيق الحسابات في ضوء المعايير الدولية " ، الطبعة الرابعة ، دار وائل

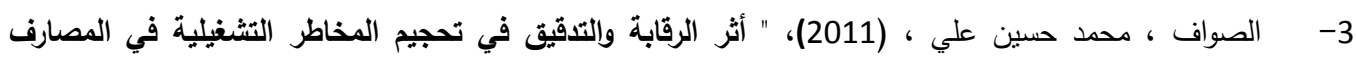

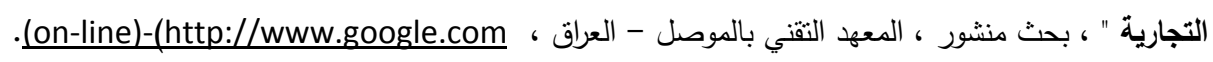

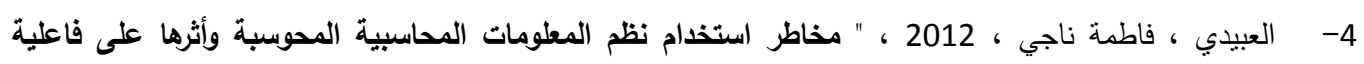

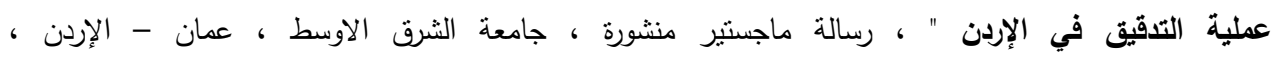
.(on-line)-(http://www.google.com 5- القاضي ودحدوح ، حسين يوسف وحسين أحمد ، 2000 ، " تدقيق الحسابات الإجراءات " ، الدار العلمية للنشر ودار الثقافة للنشر والتوزيع ، عمان - الإردن.

6- القطناني ، خالد محمود ، 2007 ، "أثر خصائص البيئة التقنية وتكنولوجيا المعلومات في مخاطر الرقابة التشغيلية

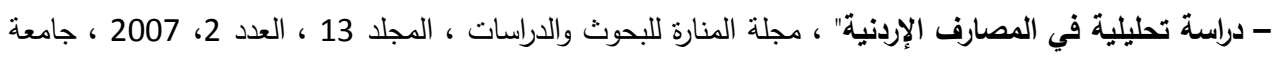

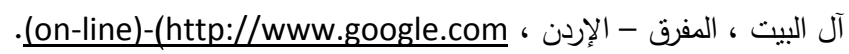
7- عبداله ، خالد أمين ، 2007 ، " علم تدقيق الحسابات " ، الطبعة الرابعة ، دار وائل للنشر والنوزيع ، عمان - 


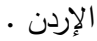

$$
\begin{aligned}
& \text { 8- نور ، عبد الناصر وعدس ، نائل ، } 2007 \text { ، " مقاييس الرقابة والأمان للبيانات المحاسبية في ظل نظام المعلومات }
\end{aligned}
$$

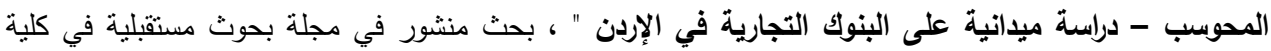

$$
\begin{aligned}
& \text { الحدباء - العدد (18) ، الموصل - العراق ، (on-line)-(http://www.google.com }
\end{aligned}
$$

9- $\quad$ Al- Kasswna, Reen Okab . (Accepted for Publication), (2012), " Electronic Accounting in Efficiency Energy Sector under Conditions of Uncertainty - A Field Study Electricity Companies in the Hashemite Kingdom of Jordan", (on-line). Available: http://www.iiste.org, Research Journal of Finance and Accounting, ISSN $2222-1697$ (Paper) ISSN 2222 - 2847, Al - Balqa Applied University - Jordan .

Harb, Rezeq . (Accepted for Publication), (2012), " The Impact of Information Systems Audit on Improving Bank's Performance", (on-line). Available: http://www.google.com , Thesis submitted, Master Degree in Accounting and Finance, Islamic University of Gaza, Palestine .

11- Nicolaou, Andreas I . (Accepted for Publication), (2000), " A Contingency Model of Perceived Effectiveness in Accounting Information Systems : Organizational Coordination and Control Effect", (on-line). Available: http://www.google.com , International Journal of Accounting Information Systems, VOL 1 , Issue 2 , Department of Business Administration, University of Piraeus , 80 Karaoli and Dimitriou Street , $185-34$ Pivaeus, Greece.

12- $\quad$ Rotich , Gladys . (Accepted for Publication), (2015), " Role of Internal Audit Function in Promoting Effective Corporate Governace of Commercial Banks in Kenya", (on-line). Available: http://www.seahipaj.org, International Journal of Business \& Law Research 3(1) : 15 - , Jan - Mar - 2015 - ISSN : 2360 - 8986, lecturer, Jomo Kenyatte University od Agriculture and technology - kenya.

13- Tucker, George . (Accepted for Publication), (2000), "IT and the Audit", (on-line). Available: http://www.journalofaccountancy.com , Journal of Accountancy , Vol , 192. 